\title{
Oral available agents in the treatment of RRMS
}

This article was published in the following Dove Press journal:

Drug, Healthcare and Patient Safety

25 October 2013

Number of times this article has been viewed

\section{Thierry Aupérin}

Medical Communications, Global MS Medical Affairs, Genzyme Corporation, Cambridge, MA, USA
Correspondence: Thierry Aupérin Medical Communications,

Global MS Medical Affairs, Genzyme Corporation, 500 Kendall Street, Cambridge, MA, USA

Tel +l 6177684360

Email thierry.auperin@genzyme.com

\section{Dear editor}

We read with interest the article by Drs Thöne and Ellrichmann entitled "Oral available agents in the treatment of relapsing remitting multiple sclerosis: an overview of merits and culprits" recently published in Drug, Healthcare and Patient Safety. ${ }^{1}$ The review provides a valuable overview of a number of new therapeutic options for multiple sclerosis (MS), with a focus on proposed mechanisms of action and efficacy and safety profiles of the respective agents.

In reading the article, however, we did note a number of errors pertaining to teriflunomide, a once-daily oral immunomodulator approved in several countries for the treatment of relapsing forms of MS (RMS) and relapsing-remitting MS (RRMS). The most significant error pertains to a statement made within the safety section, which states: "Serious adverse effects (AEs) included pathological liver function, neutropenia, and trigeminal neuralgia as well as one case of progressive multifocal leukoencephalopathy (PML) in a patient with systemic lupus erythematosus." We would like to draw the authors' attention to the fact that this case of PML pertains to the use of the related drug, leflunomide, and not teriflunomide as suggested. It is important to note that leflunomide is licensed to treat active rheumatoid arthritis in adults, and has not been evaluated or approved for the treatment of MS; as such it is inappropriate to extrapolate this observation to the use of teriflunomide. Furthermore, the case of PML cited in the article is complicated by the fact that the patient received prior multiple immunosuppressant therapies before leflunomide (ie, prednisone, azathioprine, chloroquine, danazol, cyclosporin A and methotrexate), which may have contributed to the development of PML.

Based on leflunomide exposure now reaching approximately 2.5 million patient-years (data on file, Genzyme Corporation) and a background incidence of PML estimated at 1 in 100,000 patient-years in the rheumatoid arthritis population, ${ }^{2}$ we would expect 25 cases of PML in the exposed population. However, to date, only five cases of PML have been documented in leflunomide-exposed patients, significantly fewer than expected based on the anticipated rate in this population. Furthermore, no PML cases have been reported across the entire teriflunomide clinical development program, which includes patients exposed to up to 12 years of continuous teriflunomide therapy.

We also noted a number of other instances within the teriflunomide section of the review where the distinction between leflunomide and teriflunomide becomes blurred. For example, in the final paragraph of the safety section, leflunomide evidence 
and labelling are cited in relation to use in pregnancy, but (out of date) pregnancy outcomes data are provided from the teriflunomide clinical development program.

We thank the editor for providing us with the opportunity to bring these points to the attention of the authors and the readers of Drug, Healthcare and Patient Safety.

\section{Disclosure}

The author is an employee of Genzyme Corporation. The author reports no other conflicts of interest in this communication.

\section{References}

1. Thöne J, Ellrichmann G. Oral available agents in the treatment of relapsing remitting multiple sclerosis: an overview of merits and culprits. Drug Healthc Patient Saf. 2013;5:37-47.

2. Bharat A, Xie F, Baddley JW, et al. Incidence and risk factors for progressive multifocal leukoencephalopathy among patients with selected rheumatic diseases. Arthritis Care Res. 2012;64:612-615. 


\section{Authors' reply}

Jan Thöne

Gisa Ellrichmann

Department of Neurology, St Josef Hospital Bochum, Ruhr University Bochum, Bochum, Germany

Correspondence: Jan Thöne

Department of Neurology, St Josef Hospital Bochum, Ruhr-University

Bochum, Gudrunstr 56 D-4479I, Bochum, Germany

Tel +4923450924II

Fax +4923450924I4

Email jan_thoene@gmx.de

Gisa Ellrichmann

Department of Neurology, St Josef Hospital Bochum, Ruhr-University

Bochum, Gudrunstr 56 D-4479I, Bochum, Germany

Tel +4923450924II

Fax +4923450924I4

Email gisa.ellrichmann@rub.de

\section{Dear editor}

FDA approved teriflunomide in September 2012 for the treatment of relapsing forms of multiple sclerosis (MS). Teriflunomide is an anti-inflammatory drug with immunomodulatory properties and the active metabolite of leflunomide, a disease modifying agent used in rheumatoid arthritis.

Clinical trials evaluated teriflunomide primarily in relapsing-remitting MS (RRMS). The TEMSO study also included a minor proportion of patients with progressive forms of MS. Common adverse events with teriflunomide treatment in placebo controlled trials included alopecia, increase of alanine aminotransferase, paresthesia, influenza and nausea. However, no case of progressive multifocal leukoencephalopathy (PML) is known in MS patients treated with teriflunomide. Rare cases of PML have been described in patients with rheumatoid arthritis receiving leflunomide among other immunosuppressants. ${ }^{1,2}$
We apologize for the misleading and incorrect statement that a case of PML occurred in a MS patient subsequent to treatment with teriflunomide.

So far, there are no controlled data in human pregnancy. In animal studies fetal death, fetal malformations, and decreased newborn survival are known, in animals $(<1 \times$ human dose). ${ }^{3}$ For this reason, teriflunomide is currently labeled as pregnancy category $\mathrm{X}$ and use of effective birth control is encouraged in reproductive-age females during treatment with teriflunomide. Similar to any other novel substances, postmarketing monitoring will be required to determine this issue in detail.

We are grateful to the editor for receiving the opportunity to clarify our misleading statement that a case of PML occurred in a MS patient after treatment with teriflunomide.

\section{Disclosure}

JT received funding from Teva Pharmaceuticals Ltd. GE received funding from Biogen Idec and speakers' fees from Almirall. The authors report no other conflicts of interest in this communication.

\section{References}

1. Rahmlow M, Shuster EA, Dominik J, et al. Leflunomide-associated progressive multifocal leukoencephalopathy. Arch Neurol. 2008;65(11): 1538-1539.

2. Bharat A, Xie F, Baddley JW, et al. Incidence and risk factors for progressive multifocal leukoencephalopathy among patients with selected rheumatic diseases. Arthritis Care Res. 2012;64:612-615.

3. Lu E, Wang BW, Guimond C, et al. Safety of disease-modifying drugs for multiple sclerosis in pregnancy: current challenges and future considerations for effective pharmacovigilance. Expert Rev Neurother. 2013;13:251-260.

\section{Publish your work in this journal}

Drug, Healthcare and Patient Safety is an international, peer-reviewed open-access journal exploring patient safety issues in the healthcare continuum from diagnostic and screening interventions through to treatment, drug therapy and surgery. The journal is characterized by the rapid reporting of reviews, original research, clinical, epidemiological and

\section{Dovepress}

post-marketing surveillance studies, risk management, health literacy and educational programs across all areas of healthcare delivery. The manuscript management system is completely online and includes a very quick and fair peer-review system. Visit http://www.dovepress.com/ testimonials.php to read real quotes from published authors. 